\title{
Patterns and Pedagogy: Exploring Student Blog Use in Higher Education
}

\author{
Barton K. Pursel \\ The Pennsylvania State University, United States \\ Hui Xie \\ California State University Northridge, United States
}

\begin{abstract}
As social and collaborative technologies emerge, educators and scholars continue to explore and experiment with how these tools might impact pedagogy. For over a decade, educators experimented with the use of blogs in academic settings, a tool that allows for students and instructors to enter into a rich dialogue. With most technology tools, users often leave 'digital footprints' throughout the environment. These footprints, in combination with other sources of data, allow researchers to explore relationships between the tool itself and the different types of end users. This study examines two years of institutional blog data, combined with demographic data to help describe the users of a blog platform. Different clusters of users are uncovered, and various use cases are explored, illustrating how different instructors choose to leverage blogs in the flow of a course. Using analysis of variance (ANOVA) to compare different blogging groups, results show a strong correlation between entry-dominant bloggers and growth in Grade Point Average (GPA) over time. With the rise in popularity of learning analytics, the results of this study might influence future learning analytics tools and systems.
\end{abstract}

Keywords: Blogs; Weblogs; Learning analytics; Online pedagogy

\section{Introduction}

The use of Web 2.0 tools and services continues to enhance the way people leverage the Internet throughout their daily lives. Web 2.0 is sometimes referred to as an "architecture of participation" (O'Reilly, 2005), and often involves technology environments that enable users to create, publish and share a wide variety of data. These Web 2.0 tools and services, due to their collaborative and sharing features, are good methods to build communities (Schroader, Minocha \& Schneider 2010). One Web 2.0 technology of interest, specifically in education, is a blog. Blogs often have one (or more) author that leverages the blog to create and share personal thoughts and communications that can then be commented on and linked to through various mechanisms on the web.

For over a decade, educators and scholars have explored, researched and implemented blogs in academic settings in a variety of ways. From a pedagogy standpoint, common uses of blogs include student reflection (Downes, 2004; Xie, Ke, \& Sharma, 2008), sharing ideas through authoring entries, for both student and instructor feedback via commenting (Glogoff, 2005; Ion \& 
Stingu, 2012), formative assessment for student writing (Cano \& Carbonell, 2012), and for providing an interaction space with personnel beyond the confines of a course (Oravec, 2003; Lei, Krilavicius, Zhang, Wan, \& Man, 2012). Researchers have noted a number of benefits with regard to integrating social web technologies such as blogs into learning and education. For example, students may achieve higher levels of learning through collaborating with their peers on learning projects and building a learning network over the social web (Alexander, 2006; Barnes \& Tynan, 2007). In addition, students may share their experiences and obtain positive emotional support on the social web (Schroeder et al., 2010). Finally, the fact that students showcase their work in a public web presence, such as blogs, may increase the level of realness of learning tasks (Rifkin, Longnecker, Leach, Davis, \& Orthia, 2009) and in turn increase students' motivation (Radinsky, J., Bouillion, L., Lento, E. \& Gomez, L. 2001). On the other hand, however, researchers have identified potential negative impacts social web technologies such as blogs may have on students' learning. For example, the public nature of blogs may create anxiety among some students who need to make their work visible to a broad audience (Hurlburt, 2008). Further, the adoption of social web technologies may challenge the existing rules and procedures of academic assessment and integrity (Waycott, Sheard, Thompson, \& Clerehan, 2013).

These mixed arguments and evidence highlight the need to conduct more assessments on the effect of blogging on students' learning and to obtain a deeper understanding of the relationship between blogging behaviors and learning outcomes. Most of the blog studies cited above examined blog use within a single course, or short series of courses. Therefore, this study aims to examine blog use on a university-wide scale, examining thousands of student blogs. Specifically, this study explores a complete dataset of student blogging patterns and behaviors (such as number of posts and comments), and examines the relationships between blogging pattern and academic performance in terms of cumulative GPA.

\section{Connectivism}

One lens that can help shed light on the relationship of blogs to learning is Connectivism (Siemens 2004). Connectivism posits that learning is best achieved when individuals are able to connect to a learning community, where individuals are able to interact with people of similar learning interests and aims (Boitshwarelo, 2011). According to Guder (2010), in a Connectivist model individuals need to take responsibility to build a personalized learning network filled with knowledge sources and notes relevant to individuals. Siemen's (2004) describes a number of tenants of Connectivism, several of which align nicely with the use of blogs in education:

- Learning is a process of connecting specialized nodes of information sources.

- Nurturing and maintaining connections is needed to facilitate continual learning.

- Ability to see connections between thoughts, ideas and concepts is a core skill.

The social and collaborative features of blogs, particularly those that are open and available to a large audience, theoretically might help foster a strong learning community among students. Blogs allow students to share viewpoints, opinions and critiques among one another, which differs from a traditional classroom where the instructor is often viewed as the expert and provider of knowledge (Friesen \& Lowe, 2011). Connectivism is a relatively new learning theory, and some 
scholars argue that it really isn't a theory at all, rather a pedagogical approach to learning (Kerr, 2007). For the purposes of this study, Connectivism provides a useful lens to explore institutional blog data, to address the primary research question: Do certain blogging patterns lead to changes in student performance (measured by GPA) over time?

\section{Blogging Environment}

In 2007, a large, mid-Atlantic University implemented a university-supported, centrally maintained blogging platform. The University selected Moveable Type (http://www.movabletype.org/), from Six Apart Ltd. The blogging platform supports any employee or student through unique access identification credentials provided to anyone associated with the University. For the year 2009, this included over 40,000 faculty and staff and approximately 90,000 students, spread across over 20 geographic locations across the state. In order to begin using the blog platform, a student or employee simply needs to visit the blog homepage and login. This automatically creates a blog account in the movable type system for the user. Once in the blog dashboard, users can create an infinite number of blogs that all publish to the user's University-provided webspace.

Due to the University operating and hosting the platform, all the data associated with blog utilization are stored on University servers. This allows researchers to not only aggregate and analyze the blog data alone, but to combine the blog data with institutional data from a data warehouse. What follows is an exploration of the combined blog and demographic data for 7 semesters of activity, from spring 2008 to spring 2010. Specifically, the data were used to:

- Identify adoption trends across Colleges and disciplines.

- Examine high-use blogs in an attempt to better understand emerging blogging pedagogy.

- Explore relationships between blogging and student performance.

Before moving to adoption, a brief overview of the data is warranted.

\section{Overview of Data}

The data examined were extracted from the blog platform on April $30^{\text {th }}$ of 2010 . The earliest data points were from January $11^{\text {th }}, 2008$. If the data is divided into academic semesters, the data represents blog activity from spring 2008 , summer 2008 , fall 2008 , spring 2009 , summer 2009 , fall 2009 and spring 2010 (7 semesters). Specifically, the blog data consisted of the number of blogs a user created, the number of entries and comments a user made, as well as a user's activity across other blogs (contributing entries or comments to blogs not his or her own). All the data contained timestamps. This data were then combined with data from the University's data warehouse, a clearinghouse of institutional data. The warehouse provided specific data such as student major, semester standing, semester and cumulative GPA, college and department association, course association, age and gender. In order to be included in the dataset, the employee or student must have logged into the blog system at least once, which creates a unique identification number in the platform. 


\section{Blog Adoption}

When examining the data, 19,718 unique users existed in the blog database. Most of these users, 17,791 , were classified as students. The majority of these students $(n=12,786)$ were from the University's largest campus, representing $72 \%$ of all blog users in the system. Due to a much larger student population using blogs at this specific campus, adoption data focuses on this specific cohort. When examining the 12,786 student blog users, pockets of adoption were discovered in terms of the Colleges with a high number of student blog use (Table 1).

Table 1. Student Blog Adoption Across Colleges*

\begin{tabular}{lcccc}
\hline College & Accounts & $\begin{array}{c}\text { Active } \\
\text { Accounts }\end{array}$ & $\begin{array}{c}\text { Fall 2009 } \\
\text { Population }\end{array}$ & Adoption \\
\hline Business & 1,805 & 668 & 6,103 & $11 \%$ \\
\hline Communications & 1,679 & 1,245 & 2,983 & $41 \%$ \\
\hline Engineering & 1,505 & 660 & 7,266 & $9 \%$ \\
\hline Education & 1,465 & 1,185 & 2,649 & $45 \%$ \\
\hline Liberal Arts & 1,360 & 838 & 5,802 & $14 \%$ \\
\hline Health and Human Development & 765 & 418 & 4,968 & $8 \%$ \\
\hline Information Sciences and Tech. & 685 & 447 & 1,115 & $40 \%$ \\
\hline Arts and Architecture & 541 & 324 & 1,694 & $19 \%$ \\
\hline Science & 510 & 276 & 3,894 & $7 \%$ \\
\hline Agricultural Sciences & 482 & 204 & 2,086 & $10 \%$ \\
\hline Earth and Mineral Sciences & 406 & 186 & 1,692 & $11 \%$ \\
\hline
\end{tabular}

*Students with no declared major were omitted from this table

Table 1 illustrates the number of accounts in the blog system for each College across the University's largest campus. To help better describe the data, several additional pieces of information were added. One early discovery of the blog data analysis was that many students do not actively participate on the blogs (even with a registered blog account). Nearly $44 \%$ of student blog accounts were defined as inactive, which means that the student logged into the blog platform and possibly created a blog, but posted no entries or comments on her own blog, or another blog within the system. This data point is driving an additional research initiative to better understand why so many students login to the blog platform, but record no activity.

By comparing the number of active student blog accounts per College to each College's Fall 2009 population, a rough estimation of adoption for each College is established. When considering both active accounts and College size, the College of Education (45\%), College of Communications (41\%) and the College of Information Sciences and Technology (40\%) represent the largest areas of adoption. In general, blog adoption seems sluggish within Science, Technology, Engineering and Math (STEM) fields. 


\section{Pedagogical Approaches}

With such a variety of implementations across the university, some disciplines might lean towards specific types of blog use. For instance, healthcare educators might encourage students to reflect on relevant journal articles via a blog, allowing the students to grow a collection of knowledge by the end of the semester (Maag, 2005). This method of blogging is less about collaboration, and more about individual students taking the time to think critically about academic articles. Reflection is also important in Art Education, where some educators ask students to reflect on one another's work, also offering critique (Overby, 2009). In these instances, the collaborative aspects of blogging play a key role in the learning objectives of the educator. Other disciplines, such as design fields like product design, can leverage blogs as e-portfolio spaces, allowing students to catalog various design specifications, design documents, prototypes and images from a variety of courses and internship experiences (Cochrane, Bateman, \& Flitta, 2009). In addition to providing benefits for student reflection, this e-portfolio can be a powerful tool on the job search, allowing a student to showcase her work to potential employers.

After examining blog adoption across the University's largest campus, the researchers then examined some of the most active blogs based on student entries and comments to better understand how, from a pedagogy standpoint, the blogs are used. The data were then used to create case studies and seminars for other faculty interested in adopting blogs to support learning.

In the College of Education, as well as the College of Information Sciences and Technology, many students are using blogs as an e-portfolio platform. Students, often as part of their First Year Experience ( $\mathrm{FYE})$, are required to create a blog and then update it at the end of each year with specific assignments or reflective pieces. Colleges can then use these e-portfolios as tools to assist students in locating internship and job opportunities. Some Departments leverage these eportfolios as recruiting tools, illustrating to potential students what they will learn throughout a specific academic program. Finally, some departments are leveraging e-portfolios for learning outcomes assessment, associating specific evidence contained in an e-portfolio to specific program-level learning objectives.

In the College of Communications, students leverage blogs in a variety of ways. Students use blogs in a journalism course, experimenting with writing for the Internet. In these instances, a benefit of using a blog is openness. Instructors can have alumni or corporate partners read, and respond to, student stories. This is sometimes difficult when students are posting similar stories in a Course Management System (CMS), where only students in the course can access the associated CMS space easily. One of the most commented-on blogs comes from an Introduction to Telecommunications course, where the instructor creates a single post each week, outlining and linking to the weeks' readings and homework material. At the end of the week, each student is expected to leave a comment, addressing several leading questions by the instructor.

Some faculty members are using a blog to support a collection of graduate courses, where faculty members post relevant Calls for Papers (CFPs) for education-oriented journals. Students and faculty then interact on the blog, brainstorming possible article concepts before moving forward with an article submission. Other faculty members leverage the blog platform as the online hub of a graduate course, posting the syllabi, assignments, course policies, agendas, labs, projects etc. 
One Library Faculty member leverages a blog to save, and annotate, different journal articles related to her field. This appears to be mostly personal content management, although some students have found their way to the collection and prompted some discussion. Using a blog as a personal content management system is something the data uncovered, particularly when examining faculty and staff blogs.

Faculty members teaching online often use a blog as an online communication hub. One English faculty member uses a blog to post readings, videos, and other resources the students are expected to interact with each week. The faculty member is even creating mini-lectures, leveraging a basic web cam and microphone, around certain topics and posting them to help students grasp some of the more difficult topics.

The University's Honors College requires honors scholars to leverage the blog platform. Each scholar keeps a running blog throughout her college career. The blog acts as a reflective space, specifically around different honors courses and other honors-related activities the student engages in each semester. The Honors advisers then have an active role mentoring scholars, continuing to offer frequent guidance and feedback for each scholar based on the reflections found on each student's blog.

One of the most active blogs comes from Liberal Arts, where a Philosophy instructor imports students from different courses into a single blog. Depending on the semester, this blog may have students from multiple philosophy courses all writing in the same blog space. For example, students in a 100-level introductory course might be interacting with students in an advanced, 400-level philosophy course. This is a running blog, meaning that students in subsequent semesters will be writing in the same space as students from past semesters. The blog also acts as the instructor's personal blog, where he writes about various professional organizations, critiques journal articles and books, and publishes podcasts with other prominent members of his field.

\section{Emergent Model}

The model used in the philosophy example above is being applied in several other courses now. Early indications are that this model seems to generate the most dialogue between the instructor and students, as well as dialogue among students. Students not only have the power to comment on a faculty member's entry, but also create entries. Students can also interact across course boundaries, across semester boundaries and across student standing (freshman through graduate student). External personnel, such as experts from industry or from other universities, can also participate.

One important aspect of this model is the approach to assessment. Instructors who've adopted this model typically approach assessing student activity on the blog from a holistic standpoint, meaning they assess a student's entire body of work for a semester. This is a change from some of the early models used at the University. Traditionally, an instructor might have every student create his or her own blog for a course. This approach provided the student with her own space to write and reflect, and was then visited by the professor periodically. This was problematic for a 
couple reasons. One, some instructors struggled in large courses, where they had to visit hundreds of student blogs. Two, this approach greatly diminished any chance for coherent student-tostudent discussion on a blog. Students were all in different blog spaces, making it difficult to discover one another's entries and also difficult to identify the most logical space to have specific discussions (who's blog?).

By having students all write in a single blog space, students see one another's work, driving more discourse around a topic. By assessing the student's work holistically, the instructor minimizes the risk of a landslide of activity on the blog towards the end of the semester, as students scramble to meet, for example, a blog entry requirement of 10 entries in the course. As more instructors adopt this model, discourse on course blogs is on the rise. This emergent model has led to a true knowledge sharing community, similar to those described by other blog researchers (Oravec, 2003; Kerawalla, Minocha, Kirkup, \& Conole, 2009; Hardy, Tinney, \& Davies, 2012).

\section{Learning Analytics}

The last three years witnessed the rapid growth of a field called learning analytics. Learning analytics is the "measurement, collection, analysis and reporting of data about learners and their contexts, for purposes of understanding and optimizing learning and the environment in which it occurs"(Siemens et al., 2011). Many of the current efforts around learning analytics examine student activity data, primarily within a course management system, in an attempt to better understand and predict student success (Barneveld, Arnold, \& Campbell, 2012). These systems often leverage student activity data in the CMS, combined with historical student information such as cumulative GPA, in a predictive model that helps faculty identify at-risk students early in the semester. While these efforts are laudable, the breadth of data used in these models must be more expansive in the future. As some universities are moving towards large suites of tools to support student learning, the data from tools outside of the CMS become more important to understand and include in learning analytics and predictive models. With that in mind, an effort was made to identify correlations between blogging activity and student GPA.

\section{Blogging and Student GPA}

To date, few studies have illustrated, through data, any relationship to student's academic performance as it relates to blogging. After examining basic descriptive statistics, a short exploration of student GPA over time was examined as it relates to blogging patterns.

\section{Methodology}

\section{Sample and Dataset}

For this specific data analysis, the sample consists of undergraduate students who 1) were admitted in fall 2006 to the University's main campus, and 2) made at least one comment or entry in the University's blog platform. The dataset records the blogging activities of the sample from 
spring 2008 (i.e., the semester when the blog system was launched) to fall 2009. The dataset also includes the students' cumulative GPA in the semester when their first blogging activity occurred and their cumulative GPA in spring 2010.

\section{Data Analysis}

Data were analyzed in two steps. In the first step, a K-Means cluster analysis in SPSS 19.0 was used to explore the grouping within the blog users. The cluster analysis was performed based on five variables: 1) number of entries a user made; 2 ) number of comments a user made; 3 ) number of blogs a user commented on; 4) number of blogs a user posted an entry; and 5) activity duration (i.e., number of days from account creation date to last recorded activity). Because the five variables were measured using different scales, they were standardized, using z-scores, in the cluster analysis. Several clustering solutions were produced by SPSS with each having a different number of groups. A final solution was selected based on the comparisons of the multiple clustering solutions (Hair, Black, Babin, Anderson, \& Tatham, 2006).

In the second step, the groups identified in the cluster analysis were compared in terms of the change of cumulative GPA. Repeated measure ANOVA was used to achieve this purpose. In the analysis, different blogging groups were treated as between-subject factors, while the cumulative GPAs (the semester where a student started blogging and the spring 2010 semester) were treated as repeated measures.

\section{Results}

Students were profiled in the semester when they started blogging (i.e., made the first comment or entry). The students were 21 years old on average, and fifty-six percent were female. The majority of students were from the College of Education (20\%), College of Communication (19\%), College of Business (13\%), College of Engineering (11\%), and College of Liberal Arts (10\%) (Table 2).

Table 2. College Distribution of Students

\begin{tabular}{llc}
\hline College & $\mathbf{n}$ & \% \\
\hline Education & 282 & 20.4 \\
\hline Communications & 257 & 18.6 \\
\hline Business & 183 & 13.3 \\
\hline Engineering & 152 & 11.0 \\
\hline Liberal Arts & 133 & 9.6 \\
\hline Health And Human Development & 102 & 7.4 \\
\hline Information Sciences And Technology & 72 & 5.2 \\
\hline Science & 61 & 4.4 \\
\hline Arts and Architecture & 51 & 3.7 \\
\hline Agricultural Sciences & 34 & 2.5 \\
\hline Earth and Mineral Sciences & 32 & 2.3 \\
\hline
\end{tabular}




\begin{tabular}{|c|c|c|}
\hline Undergraduate Non-Degree & 8 & 0.6 \\
\hline Division of Undergraduate Studies & 6 & 0.4 \\
\hline School of Nursing & 6 & 0.4 \\
\hline Intercollege Undergraduate Programs & 1 & 0.1 \\
\hline & 1380 & 100.0 \\
\hline
\end{tabular}

\section{Type of Student Blog Users}

2-groups, 3-groups, and 4-groups clustering solutions were compared. Solutions with five or more groups were not considered because they produced non-distinct group(s) with very small sample sizes. Groups in different solutions were compared on the five clustering variables. Results showed that a 3-groups solution is the most optimal as it produced the most distinct meaningful groups with substantive size (Figure 1). Based on their blogging activities, the three groups were labeled: entry-dominant users, comment-dominant users, and infrequent users. Table 3 shows that on average entry-dominant users made 43 entries on two blogs, but only five comments on two blogs. In contrast, comment-dominant users made 23 comments on 12 blogs, but only 13 entries on one blog. In addition, the entry-dominant users had much longer activity duration than comment-dominant users (332 days vs. 114 days). Infrequent users had low blogging activity in terms of entries, comments, and activity duration.

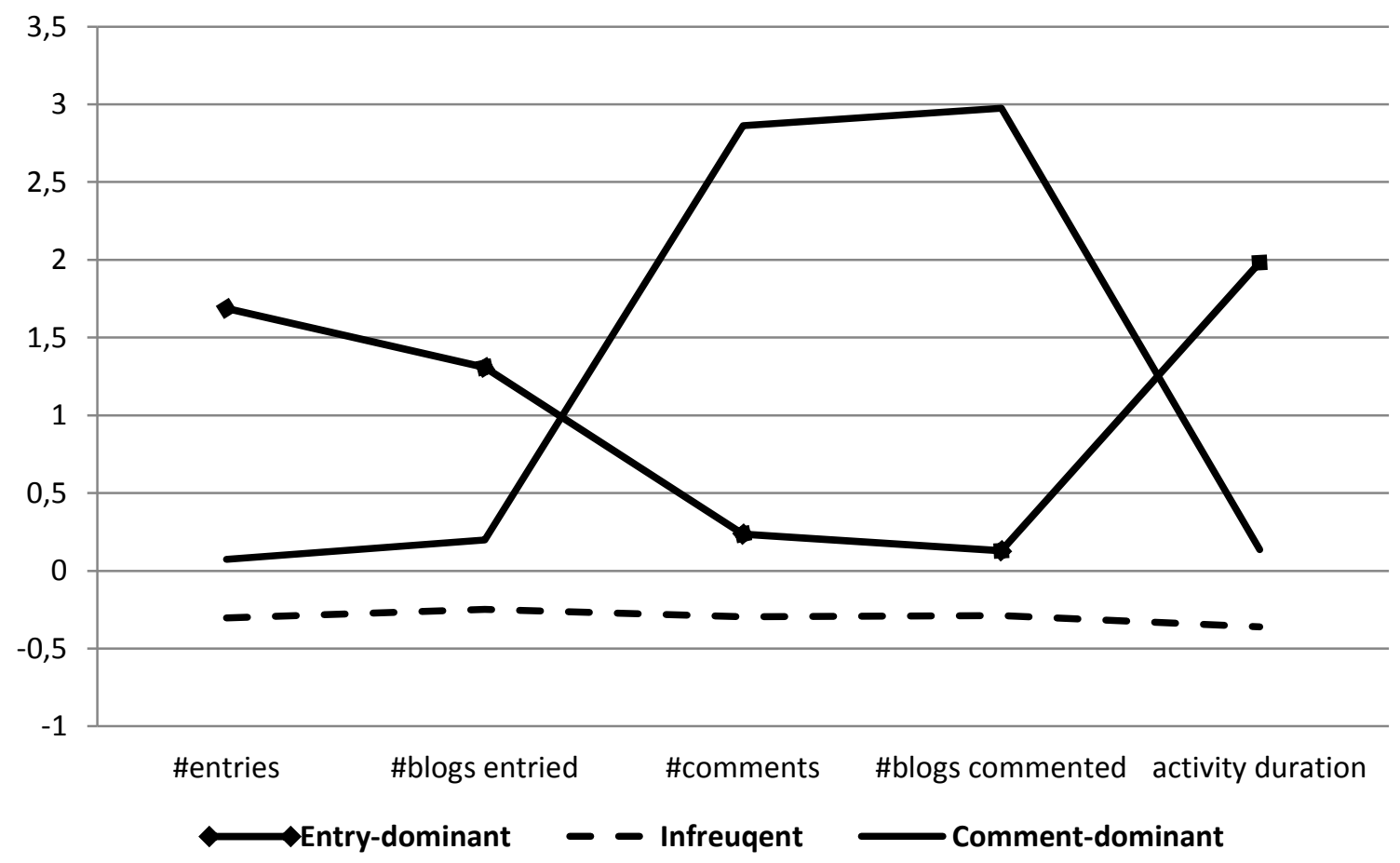

Figure 1. 3-Group Clustering Solution

Note: The clustering variables were standardized. 
Table 3. Comparison of Three Types of Blog Users

\begin{tabular}{lcccccc}
\hline Type of User & $\mathbf{N}$ & $\begin{array}{c}\text { Number } \\
\text { of entries }\end{array}$ & $\begin{array}{c}\text { Number of } \\
\text { blogs with } \\
\text { entry }\end{array}$ & $\begin{array}{c}\text { Number of } \\
\text { comments }\end{array}$ & $\begin{array}{c}\text { Number } \\
\text { of blogs } \\
\text { with } \\
\text { comment }\end{array}$ & $\begin{array}{c}\text { Activity } \\
\text { duration } \\
\text { in days }\end{array}$ \\
\hline Entry-dominant users & 192 & 42.55 & 2.38 & 5.10 & 2.09 & 331.95 \\
\hline Comment-dominant users & 97 & 13.15 & 1.38 & 22.90 & 11.78 & 114.02 \\
\hline Infrequent users & 1092 & 6.26 & .98 & 1.51 & .68 & 55.53 \\
\hline
\end{tabular}

\section{Relationship Between Blog Use and Cumulative GPA}

Table 4 illustrates the changes in cumulative GPA for three types of blog users. Results of repeated Measure ANOVA indicated that there was a significant difference among the three groups in terms of GPA change (i.e., from the semester when their first blogging activity occurred through spring 2010) $(p<.01)$. However, the results may have been somewhat biased by the drastically unbalanced sample size of infrequent users and the other two groups despite that the Type III square was used in SPSS for the adjustment. Therefore, a second repeated measure ANOVA was performed between comment-dominant and entry-dominant groups, which had similar sample size to each other. The results showed that the entry-dominant group had a significantly larger growth in cumulative GPA than the comment-dominant group $(p<.01)$ (Table 5). This indicates that the students GPA change may be affected by how they interact with blogs.

Table 4. Change of Cumulative GPA over Time: Entry-dominant Users, Comment-dominant Users, and Infrequent Users

\begin{tabular}{|c|c|c|c|c|c|c|}
\hline Type & $\mathbf{N}$ & Past GPA & $\begin{array}{c}\text { Current } \\
\text { GPA }\end{array}$ & Difference & $\boldsymbol{F}$ & Sig. \\
\hline Entry-dominant users & 192 & 3.50 & 3.56 & 0.06 & 24.329 & .000 \\
\hline Comment-dominant users & 97 & 3.36 & 3.38 & 0.02 & & \\
\hline Infrequent users & 1092 & 3.20 & 3.21 & 0.01 & & \\
\hline
\end{tabular}

Table 5. Change of Cumulative GPA over Time: Entry-dominant Users and Comment-dominant Users

\begin{tabular}{lcccccc}
\hline Type & N & Past GPA & $\begin{array}{c}\text { Current } \\
\text { GPA }\end{array}$ & Difference & $\boldsymbol{F}$ & Sig. \\
\cline { 1 - 6 } Entry-dominant users & 192 & 3.50 & 3.56 & 0.06 & 11.401 & .000 \\
\cline { 1 - 5 } Comment-dominant users & 97 & 3.36 & 3.38 & 0.02 & & \\
\hline
\end{tabular}

Since the data of this study was not collected using an experimental design, it is not possible to confirm whether the relationship between type of blog use and change in cumulative GPA was causal (Kuehl, 2000). However, the correlation documented by this study provides a promising direction for further investigation to better understand how blogging practices might impact 
student academic performance. Future research should consider using an experimental design or qausi-experimental design to further examine this relationship (Shadish, Cook, \&Campbell, 2002).

\section{Discussion}

Several intriguing questions arise after examining the blog data. The first question deals with the relatively high percentage of inactive blog users in the system. In order to be included in the data, a student must visit the blog website and login at least once. Why do so many of these students, nearly half, appear to login but never create an entry or a comment on a blog? One hypothesis is a lack of assessment aligned with the student blog assignments. Another hypothesis is that instructors do not properly model the behavior expected from students. In order for students to accept and contribute to the blogs in the flow of a course, the instructor should first model the types of behavior on the blog that she expects to see from students (Hsu \& Lin, 2008). Without this form of modeling, or past blog entries to review, students might not comprehend exactly how they should leverage a course blog.

Another question around adoption deals with disciplines. STEM fields seem to leverage the blog infrequently. While blogs are often viewed as a place to write online, several pedagogies emerged from this study that appears to lend themselves to all types of instruction. For instance, STEM professors can easily record small, instructional videos focusing on a specific topic and use the blog as the delivery mechanism. Many STEM fields are also portfolio driven, such as Engineering, and the blog platform currently supports several portfolio efforts in the College of Education. Similar templates can be easily applied to STEM fields.

When examining blog data as it relates to learning analytics, the data suggest that entry-dominant bloggers see the largest performance gains from blogging. The separation between entrydominant and comment-dominant bloggers with regards to the duration of their blogging is also an interesting discovery. It appears that comment dominant bloggers might only blog for the duration of a course, while entry-dominant bloggers are writing entries for nearly a year on average. Because comment-dominant users were spread across various blogs, they may not have a strong sense of ownership of the content on a blog, which in turn may have a negative impact on their motivation to blog over time. How can this participation gap be bridged, attempting to migrate more comment-dominant bloggers to write more entries and stay active in the blog platform longer?

The relationship between blogging pattern and academic performance documented in this study may, to some extent, confirm the notion of Connectivism, which posits that to achieve effective learning, individuals need to build a personally relevant learning networks. The inactive bloggers in this study obviously failed to build any networks. The comment-dominant bloggers also may be unsuccessful in building an effective and personalized learning network because they did not create a sufficient number of entries to establish their own learning topics, although they may be contributing to other people's learning networks by providing comments. The entry-dominant bloggers may be the group that build and maintain the learning network most successfully, and as a result, learn most through blogging. Due to the large volume of blogs, many existing in different contexts, it is difficult to apply Connectivism at a large scale. Though when exploring the specific 
emergent model from the Liberal Arts Philosophy course, Connectivism does seem applicable and students do appear to be exhibiting the tenants of Connectivism in the formation and fostering of a dynamic knowledge sharing community exhibited on their blog.

As institutions continue to explore learning analytics, what role does blog data play in the larger data mining activities that underlie many of the predictive models that power learning analytics software? Most of the data comes from course management systems, where it is assumed students spend a significant amount of time. By understanding more about the patterns and potential impact blogging has on student performance, what types of blog data should be included in analytics software? How much weight should be put on variables such as blog comments and entries? After examining the relationship between blogging and student performance, would a social network analysis of blog users also unveil a connection between blogging habits and student performance?

\section{Conclusion}

This study uncovered basic patterns of blogging activity, as well as interesting pedagogical examples of how blogs might be leveraged in education. The study also identified a correlation between various blogging patterns and student performance in terms of GPA changes over time. While this data suggests blogs play some role in student learning, it is clear more research is required to better understand the role of blogs in the learning process. As researchers move forward, specific studies focusing on a variety of pedagogical methods are recommended.

This study identified many examples of blog use that, historically, do not resemble a traditional blog. For example, students and faculty are sometimes using the blog for personal content management, allowing for the capture, annotation and archiving of relevant information over time. Other students and faculty are using the blog platform to simply publish a static website, such as an e-portfolio. As blogging tools mature, researchers should continue to discover and document innovative uses of blogs uncovered through data, and share broadly with the educational technology community.

\section{References}

Alexander, B. (2006). Web 2.0: A new wave of innovation for teaching and learning? Educause Review, 41(2), 32-44.

Barnes, C. \& Tynan, B. (2007). The adventures of Miranda in the brave new world: Learning in a Web 2.0 millennium. Association for Learning Technology Journal, 15(3), 189-200.

Barneveld, A., Arnold, K., \& Campbell, J. (2012). Analytics in higher education: Establising a common language. Retrieved from http://net.educause.edu/ir/library/pdf/ELI3026.pdf

Boitshwaelo, B. (2011). Proposing an integrated research framework for Connectivism: Utilising theoretical synergies. International Review of Research in Open and Distance Learning, 12(3), 161-179. 
Cano, E., Carbonell, M. R., Lanzo, N. C., \& Ion, G. (2012). Developing assessment practices through the use of blogs in higher education: An innovative experience in the open university of Catalonia (pp. 300-305). Presented at the eLearning and Software for Education, Bucharest.

Cochrane, T., Bateman, R., \& Flitta, I. (2009). Integrating mobile web 2.0 within tertiary education. In A. Méndez-Vilas, A. Solano Martin, J. A. Mesa González, \& J. Mesa González (Eds.), Research, reflections and innovations in integrating ICT in education(pp. 1348-1352). Badajoz, Spain: FORMATEX.

Downes, S. (2004). Educational blogging. Educause Review, 39(5), 14-26.

Friesen, N. \& Lowe, S. (2011) The questionable promise of social media for education: Connective learning and the commercial imperative. Journal of Computer Assisted Learning, 28(3), 183194.

Glogoff, S. (2005). Instrucitonal blogging: Promoting interactivity, student-centered learning, and peer input. Innovate, 1(15).

Guder, C. (2010). Patrons and pedagogy: A look at the theory of Connectivism. Public Services Quartley, 6(1), 36-42.

Hair, J. F., Black, W. C., Babin, B. J., Anderson, R. E., \&Tatham, R. L. (2006).Multivariate data analysis (6th ed.). Upper Saddle River, NJ: Pearson Education.

Hardy, A., Tinney, J., \& Davies, S. (2012). Using e-portfolios to support trainee design and technology teachers in developing their subject knowledge. Presented at the Pupil's Attitude Towards Technology (PATT). Stockholm, Sweden.

Hsu, C. \& Lin, J. (2008). Acceptance of blog usage: The roles of technology acceptance, social influence and knowledge sharing motivation. Information \& Management, 45(1), 65-74.

Hurlburt, S. (2008). Defining tools for a new learning space: Writing and reading class blogs. MERLOT Journal of Online Learning and Teaching, 4(2), 182-189.

Ion, G. \& Stingu, M. (2012). Learning pedagogy through blogs: An experience in initial teacher training. Presented at the eLearning and Software for Education, Bucharest.

Kerawalla, L., Minocha, S., Kirkup, G., \& Conole, G. (2009). An empirically grounded framework to guide blogging in higher education. Journal of Computer Assisted Learning, 25(1), 31-42.

Kerr, B. (2007). A challenge to Connectivism. Retrieved on 9 April 2013 from http://learningevolves.wikispaces.com/kerr

Kuehl, R. O. (2000). Design of experiments: Statistical principles of research design and analysis. Pacific Grove, CA: Duxbury/Thomson Learning.

Lei, C., Krilavicius, T., Zhang, N., Wan, K., \& Man, K. (2012). Using web 2.0 tools to learning in higher education: A case study in technological education. Paper presented at the International Multiconference of Engineers and Computer Scientists. Hong Kong.

Maag, M. (2005). The potential use of "Blogs" in nursing education. CIN: Computers, Informatics, Nursing, 23(1), 16-24.

Oravec, J. A. (2003). Blending by blogging: weblogs in blended learning initiatives. Journal of educational media, 28(2-3), 225-233. 
O'Reilly, T. (2005). What is Web 2.0. - Design patterns and business models for the next generation of software. Retrieved on 12 April 2014 from http://oreilly.com/web2/archive/what-is-web20.html.

Overby, A. (2009). The new conversation: Using weblogs for reflective practice in the studio art classroom. Art Education, 62(4), 18-24.

Radinsky, J., Bouillion, L., Lento, E. \& Gomez, L. (2001). Mutual benefit partnership: A curricular design for authenticity. Journal of Curriculum Studies, 33(4), 405-430.

Rifkin, W., Longnecker, N., Leach, J., Davis, L., \& Orthia, L. (2009). Motivate students by having them publish in new media: an invitation to science lecturers to share and test. Proceedings of the Uniserve Science Conference. Sydney, Australia.

Schroeder, A., Minocha, S., \& Schneider, C. (2010). The strengths, weaknesses, opportunities, and threats of using social software in higher and further education teaching and learning. Journal of Computer Assisted Learning, 26(3), 159-174.

Shadish, W. R., Cook, T. D., \& Campbell, D. T. (2002). Experimental and quasi-experimental designs for generalized causal inference. New York: Houghton Mifflin Company.

Siemens, G. (2004). Connectivism: A learning theory for the digital age. Retrieved on 15 March 2014 from http://itdl.org/journal/jan_05/article01.htm.

Siemens, G., Gasevic, D., Haythornthwaite, C., Buckingham Shum, S., Ferguson, R., \& Duvel, E. (2011). Open learning analytics: An integrated and modularized platform. Paper presented at the Learning Analytics and Knowledge. Banff, Alberta, Canada.

Waycott, J., Sheard, J., Thompson, C., \& Clerehan, R. (2013) Making students' work visible on the social web: A blessing or a curse? Computers \& Education, 68, 86-59.

Xie, Y., Ke, F., \& Sharma, P. (2008). The effect of peer feedback for blogging on college students' reflectinve learning processes. Internet and Higher Education, 11(1), 18-25.

Correspondence: Bart K. Pursel, Co-Director, Center for Online Innovation in Learning, The Pennsylvania State University, 202C Rider Building, University Park, Pennsylvania, United States 